\title{
Hydration of Atmospheric Molecular Clusters III : Procedure for Efficient Free Energy Surface Exploration of Large Hydrated Clusters
}

\section{Rasmussen, Freja Rydahl}

2020-06-25

Rasmussen, F R, Kubecka, J , Besel , V, Vehkamäki, H, Mikkelsen, K V, Bilde , M \& Elm , J 2020 , ' Hydration of Atmospheric Molecular Clusters III : Procedure for Efficient Free Energy Surface Exploration of Large Hydrated Clusters ' , Journal of Physical Chemistry A, vol. 124 , no. 25 , pp. 5253-5261 . https://doi.org/10.1021/acs.jpca.0c02932

http://hdl.handle.net/10138/330315

https://doi.org/10.1021/acs.jpca.0c02932

unspecified

acceptedVersion

Downloaded from Helda, University of Helsinki institutional repository.

This is an electronic reprint of the original article.

This reprint may differ from the original in pagination and typographic detail.

Please cite the original version. 


\section{Hydration of Atmospheric Molecular Clusters III: Procedure for Efficient Free Energy Surface Exploration of Large Hydrated Clusters}

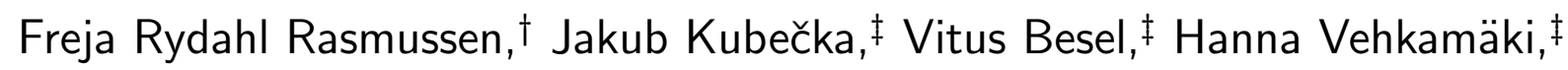
Kurt V. Mikkelsen, ${ }^{*}$, Merete Bilde, ${ }^{\S}$ and Jonas Elm ${ }^{*}$,

†Department of Chemistry, Aarhus University, Langelandsgade 140, 8000 Aarhus, Denmark $\ddagger$ Institute for Atmospheric and Earth System Research, University of Helsinki, Helsinki FI-00014, Finland

IDepartment of Chemistry, University of Copenhagen, Universitetesparken 5, 2100 Copenhagen, Denmark

§Department of Chemistry and iClimate, Aarhus University, Langelandsgade 140, 8000 Aarhus, Denmark

E-mail: kmi@chem.ku.dk; jelm@chem.au.dk Phone: +4528938085 


\begin{abstract}
Sampling the shallow free energy surface of hydrated atmospheric molecular clusters is a significant challenge. Using computational methods we present an efficient approach to obtain minimum free energy structures for large hydrated clusters of atmospheric relevance. We study clusters consisting of two to four sulfuric acid (sa) molecules and hydrate them with up to five water (w) molecules. The structures of the "dry" clusters are obtained using the ABCluster program to yield a large pool of low-lying conformer minima with respect to free energy. The conformers (up to ten) lowest in free energy are then hydrated using our recently developed systematic hydrate sampling technique. Using this approach, we identify a total of 1145 unique $(\mathrm{sa})_{2-4}(\mathrm{w})_{1-5}$ cluster structures. The cluster geometries and thermochemical parameters are calculated at the $\omega \mathrm{B} 97 \mathrm{X}-\mathrm{D} / 6-31++\mathrm{G}(\mathrm{d}, \mathrm{p})$ level of theory, at $298.15 \mathrm{~K}$ and 1 atm. The single point energy of the most stable clusters is calculated using a high level DLPNO-CCSD $\left(\mathrm{T}_{0}\right)$ /aug-cc-pVTZ method. Using the thermochemical data, we calculate the equilibrium hydrate distribution of the clusters under atmospheric conditions and find that the larger $(\mathrm{sa})_{3}$ and $(\mathrm{sa})_{4}$ clusters are significantly more hydrated than the smaller $(\mathrm{sa})_{2}$ cluster or the sulfuric acid $(\mathrm{sa})_{1}$ molecule. These findings indicate that more than five water molecules might be required to fully saturate the sulfuric acid clusters with water under atmospheric conditions. The presented methodology gives modellers a tool to take the effect of water explicitly into account in atmospheric particle formation models based on quantum chemistry.
\end{abstract}




\section{Introduction}

Poor fundamental understanding of the initial formation and growth of atmospheric aerosol particles persist as the largest uncertainty in predicting our current and future climate. ${ }^{1}$ Aerosol particles residing in the atmosphere cool the Earth's surface by scattering incoming sunlight back into space. By uptake of water vapour, aerosol particles can act as cloud condensation nuclei and influence the albedo and precipitation patterns of clouds. Up to half the number of cloud condensation nuclei are believed to originate from the formation of new particles from gas phase vapours ${ }^{2}$ via molecular clustering. ${ }^{3}$ The ambient atmosphere contains large quantities of water vapour, which can significantly affect cluster formation via hydrogen bonding with polar molecules in the vapor phase, however, the exact chemical nature of the participating vapours in forming new particles remain ambiguous. Sulfuric acid, together with water, is believed to be a principal component in new particle formation and sulfuric acid concentrations have been shown to correlate directly with observed new particle formation events. ${ }^{4}$ The two component sulfuric acid - water system is capable of forming clusters at high altitudes, due to the low temperatures and the fact that there are no competing formation channels, and thus is responsible for the formation of stratospheric sulfur aerosols known as the "junge layer". ${ }^{5}$ In the lower atmosphere other stabilizing vapour molecules, such as atmospheric bases ${ }^{6}$ and highly oxidized organic compounds, ${ }^{7}$ are required to facilitate the particle formation process. In particular trace species with high basicities such monoamines, ${ }^{8-14}$ diamines ${ }^{15-17}$ or guanidine ${ }^{18-20}$ are potent candidates to stabilize sulfuric acid clusters and enhance new particle formation in the lower troposphere.

It is challenging to obtain direct experimental information about the atmospheric cluster composition. Using electrospray ionization (ESI), clusters can be formed in situ and measured with mass spectrometry techniques in the laboratory. ${ }^{21}$ Applying, for instance, cryogenic infrared techniques, it is possible to obtain molecular level structural information about the cluster structure. ${ }^{22}$ Using chemical ionization atmospheric pressure time of flight mass spectrometry (CI-API-TOF), ${ }^{23}$ direct online information about the cluster composi- 
tion can also be obtained. However, the ionization technique requires that the clusters are charged in order to be detected, and the charging process might lead to fragmentation inside the instrument. ${ }^{24,25}$ Especially, water is difficult to measure using these techniques as the energy added in the ionization process causes instant evaporation of most water molecules that might have been present. ${ }^{26,27}$

Numerous studies on atmospheric cluster formation using quantum chemical calculations exist, but the inclusion of water molecules is still not a standard procedure. This is caused by the fact that each water molecule in the cluster severely complicates the search for the lowest free energy configuration as the potential free energy surfaces are quite shallow. This is evident from the still ongoing exploration of the potential energy surface of the simple pure water clusters. ${ }^{28-36}$ The hydration of a single sulfuric acid molecule, ${ }^{37-43}$ as well as the hydration of the sulfuric acid dimer, ${ }^{44-46}$ have previously been studied extensively using quantum chemical methods. Larger $\left(\mathrm{H}_{2} \mathrm{SO}_{4}\right)_{1-2}\left(\mathrm{H}_{2} \mathrm{O}\right)_{0-5}{ }^{47}$ and $\left(\mathrm{H}_{2} \mathrm{SO}_{4}\right)_{1-4}\left(\mathrm{H}_{2} \mathrm{O}\right)_{1-5}{ }^{48}$ clusters have been studied using quantum chemical methods by Loukonen et al. and Henschel et al., respectively. However, the sampling of these large clusters was unlikely to be sufficient as it was performed using molecular dynamics or by hand based on chemical intuition. Kildgaard et al., recently proposed a systematic hydrate sampling approach, ${ }^{49}$ which has been applied efficiently to study the hydration of a single sulfuric acid molecule with up to 15 water molecules and the hydration of three different atmospheric relevant organic acids with up to 10 water molecules. ${ }^{50}$ In this paper, we present a procedure for efficiently sampling the configurational space of large hydrated clusters of atmospheric relevance using the binary sulfuric acid - water cluster system as a test system. We apply the ABCluster program $^{51,52}$ to obtain the free energy minimum structures of the"dry" $(\mathrm{sa})_{1-4}$ clusters, and subsequently, apply the systematic hydrate sampling approach by Kildgaard et al. to add up to five water molecules to the clusters. 


\section{Methods}

\subsection{Computational Details}

The Gaussian 16 program was used in all geometry optimizations and vibrational frequency calculations. ${ }^{53}$ The Gaussian $09^{54}$ defaults were used and the rigid-rotor and harmonic oscillator approximations were employed in all calculations. We employed the $\omega$ B97X-D functional as it has demonstrated superior performance compared to other density functionals in yielding binding energies in agreement with higher level methods such as $\operatorname{CCSD}(\mathrm{T}) .{ }^{55,56} \mathrm{We}$ used a $6-31++G(d, p)$ basis set as it has been shown to be a cost-effective choice to obtain the molecular structures and thermal contributions to the free energy without introducing significant errors compared to larger basis sets. ${ }^{57,58}$

The ORCA 4.2.0 program was employed for all single point energy calculations with the DLPNO-CCSD $\left(\mathrm{T}_{0}\right)$ method. ${ }^{59,60}$ The DLPNO-CCSD $\left(\mathrm{T}_{0}\right)$ method has previously shown excellent performance for the large GMTKN55 test set. ${ }^{61}$ We used an aug-cc-pVTZ basis set with the corresponding /C and /JK auxiliary basis sets for density fitting and Coulomb/exchange fitting in the Hartree-Fock calculation, respectively. The DLPNO-

$\operatorname{CCSD}\left(\mathrm{T}_{0}\right) /$ aug-cc-pVTZ level of theory with a NormalPNO criterion ${ }^{62}$ has been shown to be a cost efficient approach to obtain binding energies of atmospheric molecular clusters which are in good agreement with $\operatorname{CCSD}(\mathrm{T})$ complete basis set estimates. ${ }^{56,63}$ Furthermore, it has been shown that using a TightPNO criterion does not improve the calculated energetic compared to benchmark CCSD(T)/CBS estimates ${ }^{56,63}$ and for a test set of 139 (sa)(w) ${ }_{1-9}$ clusters. ${ }^{49}$ Thus a NormalPNO criterion was chosen. We applied the semi-canonical $\left(\mathrm{T}_{0}\right)$ approximation for calculating the perturbative triples correction as it was shown recently that the improved iterative $(\mathrm{T})$ approximation ${ }^{64}$ yielded identical performance for a test set of 45 atmospheric dimer formation reactions. ${ }^{63}$ 


\section{Results and Discussion}

\subsection{Hydrate Sampling Procedure}

The initial "dry" $(\mathrm{sa})_{2-4}$ structures of the clusters were taken from Kubečka et al. ${ }^{65}$ where the clusters have been generated using the ABCluster program. ${ }^{51,52}$ Initially, the clusters were optimized using GFN-xTB ${ }^{66}$ and narrowed down based on different thresholds of $0.01 \AA$, 0.001 Hartree, and 0.1 Debye for the radius of gyration, the energy, and the dipole moment, respectively. Subsequently, the molecular structures of the identified conformations were optimized at the $\omega \mathrm{B} 97 \mathrm{X}-\mathrm{D} / 6-31++\mathrm{G}(\mathrm{d}, \mathrm{p})$ level of theory. This procedure generated a large pool of initial conformers for the $(\mathrm{sa})_{2-4}$ cluster system. We used up to 10 conformers lowest in free energy as starting point for hydrating the clusters. The hydrated clusters were sampled using the systematic configurational sampling algorithm presented by Kildgaard et al. ${ }^{49,50}$ In brief, the method generates a number of points $(n=10)$ evenly distributed around

each atom using Fibonacci spheres and excluding all points that are within $0.5 \AA$ of each other. Subsequently, a water molecule is placed at each point in three different orientations. To add water molecules to the core of the cluster we locate existing hydrogen bond pairs and radially translate the cluster away from the midpoint of the pairs to allow space for a water molecule. This procedure generates a uniform distribution of water molecules around the cluster with 800-1200 initial input conformations for each cluster geometry. Subsequently, each conformation is optimized and vibrational frequencies are calculated using the PM7 method. ${ }^{67}$ The conformations are then sorted and the initial number of clusters reduced based on their relative free energy (cut-off of $3.0 \mathrm{kcal} / \mathrm{mol}$ relative to the lowest free energy conformer), and rotational constants. Finally, the clusters are optimized and vibrational frequencies are calculated at the $\omega \mathrm{B} 97 \mathrm{X}-\mathrm{D} / 6-31++\mathrm{G}(\mathrm{d}, \mathrm{p})$ level of theory. The resulting mono-hydrated $(\mathrm{sa})_{2-4}(\mathrm{w})_{1}$ clusters are then subjected to another hydration step using the same procedure in a sequential manner to finally obtain the entire set of the $(\mathrm{sa})_{2-4}(\mathrm{w})_{1-5}$ clusters. After all the clusters were optimized at the DFT level, a DLPNO-CCSD $\left(\mathrm{T}_{0}\right) /$ aug- 
cc-pVTZ calculation was performed on the three cluster structures lowest in free energy. The final approximate DLPNO-CCSD $\left(\mathrm{T}_{0}\right)$ binding free energy was then calculated as:

$$
\Delta G_{\text {bind }}^{\mathrm{DLPNO}-\mathrm{CCSD}\left(\mathrm{T}_{0}\right)}=\Delta E_{\text {bind }}^{\mathrm{DLPNO}-\mathrm{CCSD}\left(\mathrm{T}_{0}\right)}+\Delta G_{\text {therm }}^{\omega \mathrm{B} 97 \mathrm{X}-\mathrm{D}}
$$

Where $\Delta E_{\text {bind }}^{\mathrm{DLPNO}-\mathrm{CCSD}\left(\mathrm{T}_{0}\right)}$ is the electronic binding energy and $\Delta G_{\text {therm }}^{\omega \mathrm{B} 97 \mathrm{X}-\mathrm{D}}$ is the thermal contribution to the free energy, respectively, defined as:

$$
\begin{aligned}
\Delta E_{\text {bind }}^{\mathrm{DLPNO}} & =E_{\text {bind, cluster }}^{\mathrm{DLPNO}\left(\mathrm{T}_{0}\right)}-\sum E_{\text {bind, monomers }}^{\mathrm{DLPNO} C \mathrm{CCSD}\left(\mathrm{T}_{0}\right)} \\
\Delta G_{\mathrm{therm}}^{\omega \mathrm{B} 97 \mathrm{X}-\mathrm{D}} & =G_{\text {therm, cluster }}^{\omega \mathrm{B} 97 \mathrm{X}-\mathrm{D}}-\sum G_{\text {therm, monomers }}^{\omega \mathrm{B} 97 \mathrm{X}-\mathrm{D}}
\end{aligned}
$$

A schematic overview of the sampling process is outlined in Figure 1:

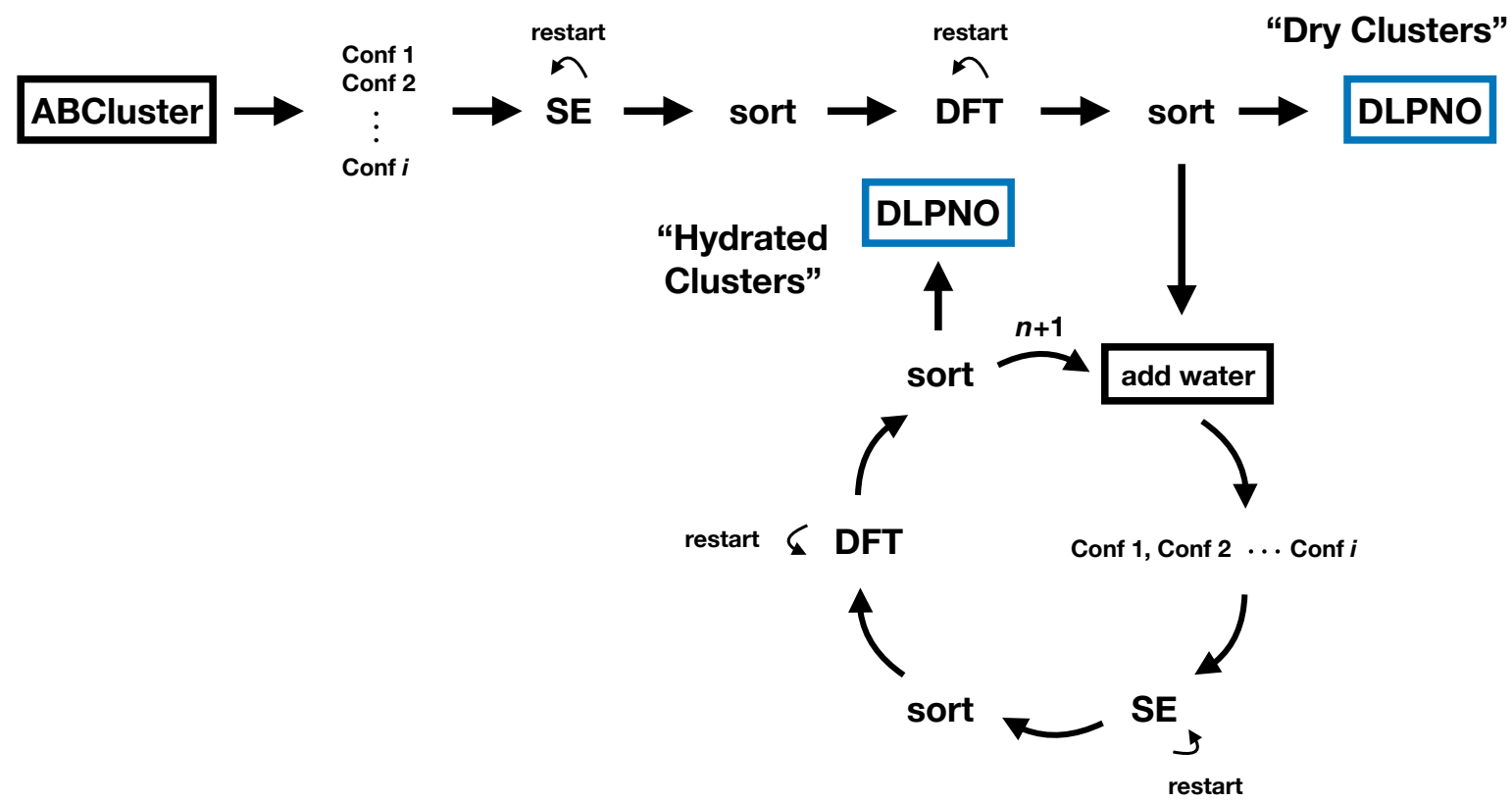

Figure 1: Schematic overview of the sampling process of the $(\mathrm{sa})_{2-4}(\mathrm{w})_{n}$ clusters, with $n$ up to five. SE refers to semi-empirical methods and DFT refers to density functional theory. The linear top "track" of the flow chart for obtaining the dry clusters outlines a workflow as described by Temelso et al. ${ }^{68}$ and Kubečka et al. ${ }^{65}$ The lower cyclic track outlines the consecutive addition of water molecules as described in this work. 
There are other options for the semi-empirical (SE) and DFT methods used in the sampling process. We chose the $\omega \mathrm{B} 97 \mathrm{X}-\mathrm{D}$ density functional based on numerous benchmarks of cluster binding energies. ${ }^{55-57,63,69}$ The sorting mechanism can also be based on properties (energies, dipole moments, ect) or on the molecular structure instead of the free energies. "restart" in Figure 1 refers to restarting calculations that might not have converged due to a too disadvantagous starting geometry. In the present manuscript we did not restart the SE methods, but the DFT calculations were restarted 1-3 times. The clusters were sorted semi-manually based on the free energies and rotational constants to ensure that too similar molecular structures were not included.

\subsection{Cluster Structures}

Utilizing the approach outlined in Figure 1 we identified a total of 1145 unique $(\mathrm{sa})_{2-4}(\mathrm{w})_{1-5}$ cluster structures. All the cluster structures and thermochemistry have been added to the Atmospheric Cluster Database (ACBD). ${ }^{70}$ The identified cluster structures lowest in free

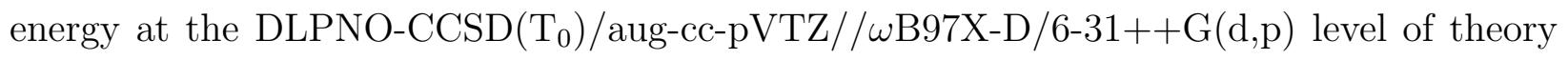
(298.15 K and $1 \mathrm{~atm})$ are presented in Figure 2. It should be mentioned that applying the DLPNO-CCSD $\left(\mathrm{T}_{0}\right) /$ aug-cc-pVTZ energy correction in some cases led to a change in the ordering of the conformers with respect to their free energy. This is a consequence of the conformers lying very close in free energy. 


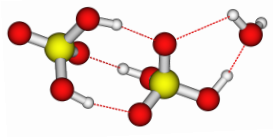

$(\mathrm{sa})_{2}(\mathrm{w})_{1}$

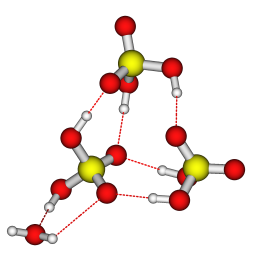

$(\mathrm{sa})_{3}(\mathrm{w})_{1}$

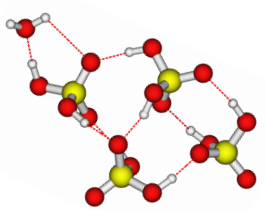

$(\mathrm{sa})_{4}(\mathrm{w})_{1}$

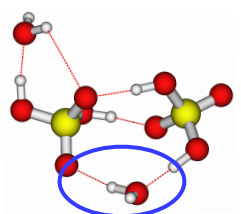

$(\mathrm{sa})_{2}(\mathrm{w})_{2}$

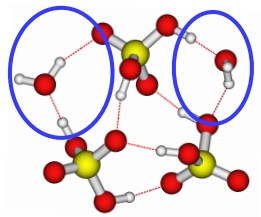

$(\mathrm{sa})_{3}(\mathrm{w})_{2}$

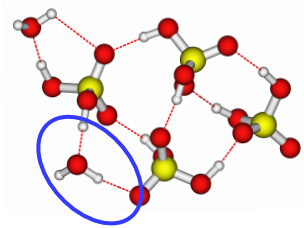

$(\mathrm{sa})_{4}(\mathrm{w})_{2}$

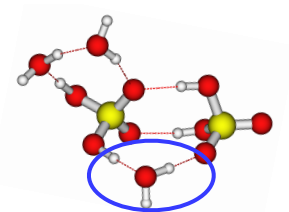

$(\mathrm{sa})_{2}(\mathrm{w})_{3}$

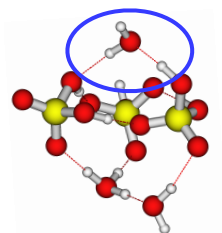

$(\mathrm{sa})_{3}(\mathrm{w})_{3}$

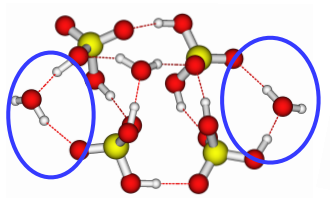

$(\mathrm{sa})_{4}(\mathrm{w})_{3}$

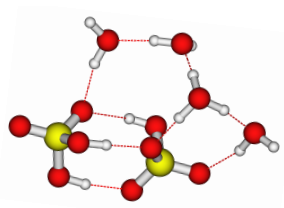

(sa) $)_{2}(w)_{4}$

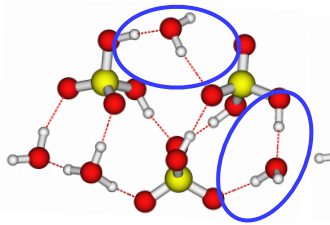

$(\mathrm{sa})_{3}(\mathrm{w})_{4}$

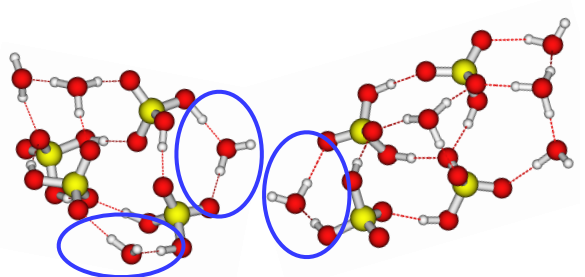

$(\mathrm{sa})_{4}(\mathrm{w})_{4}$

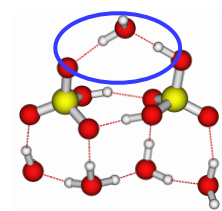

(sa) $)_{2}(w)_{5}$

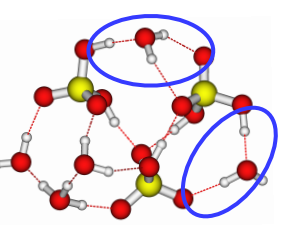

$(\mathrm{sa})_{3}(\mathrm{w})_{5}$

Figure 2: Molecular structure of the identified lowest free energy $(\mathrm{sa})_{2-4}(\mathrm{w})_{1-5}$ clusters, at DLPNO-CCSD $\left(\mathrm{T}_{0}\right) /$ aug-cc-pVTZ// $\omega$ B97X-D/6-31++G(d,p) level of theory $(298.15 \mathrm{~K}$ and 1 atm). The clusters have been optimized at the $\omega B 97 X-D / 6-31++G(d, p)$ level of theory. The blue circles encompasses a recurring hydrogen bond pattern found in most of the cluster structures. Yellow $=$ sulfur, red $=$ oxygen and grey $=$ hydrogen .

For most of the cluster structures we identify a recurring hydrogen bond pattern S$\mathrm{OH} \cdots \mathrm{O}(\mathrm{H}) \mathrm{H} \cdots \mathrm{O}=\mathrm{S}$ (shown by the blue circles in Figure 2). This pattern "bridges" two sulfuric acid molecules and the fact that it is identified in most of the lowest free energy cluster structures implies that it might significantly contribute to the stability of the clusters. A similar hydrogen bond pattern has been identified in $\left(\mathrm{HSO}_{4}^{-}\right)_{1}\left(\mathrm{H}_{2} \mathrm{SO}_{4}\right)_{1-2}\left(\mathrm{H}_{2} \mathrm{O}\right)_{0-6}{ }^{71}$ and $\left(\mathrm{HSO}_{4}^{-}\right)_{2}\left(\mathrm{NH}_{4}^{+}\right)_{3}\left(\mathrm{H}_{2} \mathrm{O}\right)_{0-4}{ }^{72}$ clusters using infrared multiple photon dissociation and cryogenic ion vibrational predissociation spectroscopy techniques. It should be mentioned that the cluster structures currently in the cluster database only have the this type of hydrogen bond pattern in a few of the cluster structures. In the $(\mathrm{sa})_{3}(\mathrm{w})_{3}$ and generally in clusters containing 4-5 water molecules, we observe a proton transfer from one sulfuric acid molecule to one of the water molecules.

As illustrated in Figure 2 there can be a large molecular rearrangement from the $n-1$ 
to the $n$ water cluster. This implies that the lowest free energy cluster conformation of the $n-1$ cluster might not lead to the lowest free energy conformation of the $n$ water cluster when performing the sampling. Table 1 presents the conformation number $\left(\mathrm{Conf}_{n-1}\right.$ \#, with increasing free energy for Conf 1 , Conf $2, \ldots$, Conf $i$ ) for the $n-1$ water cluster that leads to the lowest free energy of the $n$ cluster. Table 1 also compares our newly sampled cluster structures and thermochemistry to the clusters available in the literature i.e. the atmospheric cluster database. ${ }^{70}$ Here $\Delta \Delta G_{n}$ shows the Gibbs free energy difference (in $\mathrm{kcal} / \mathrm{mol}$ ) compared to the same cluster currently in the atmospheric cluster database. ${ }^{70}$ All clusters are compared at the DLPNO-CCSD $\left(\mathrm{T}_{0}\right) /$ aug-cc-pVTZ// $\mathrm{B} 97 \mathrm{X}-\mathrm{D} / 6-31++\mathrm{G}(\mathrm{d}, \mathrm{p})$ level of theory, $298.15 \mathrm{~K}$ and $1 \mathrm{~atm}$.

Table 1: Conf $_{n-1}$ \# shows the conformation number of the $n-1$ water cluster in the hydrate sampling that leads to the lowest free energy conformer of the $n$ water cluster. The cluster conformations are numbered with increasing free energy for Conf 1 , Conf $2, \ldots$, Conf $i$. $\Delta \Delta G_{n}$ present the Gibbs free energy change (in $\mathrm{kcal} / \mathrm{mol}$ ) compared to the same cluster in the atmospheric cluster database ${ }^{70}$

\begin{tabular}{ccc}
\hline \hline Cluster & Conf $_{n-1} \#$ & $\Delta \Delta G_{n}$ \\
\hline \hline$(\mathrm{sa})_{2}(\mathrm{w})_{1}$ & Conf 3 & -0.9 \\
$(\mathrm{sa})_{2}(\mathrm{w})_{2}$ & Conf 2 & -0.8 \\
$(\mathrm{sa})_{2}(\mathrm{w})_{3}$ & Conf 2 & -1.1 \\
$(\mathrm{sa})_{2}(\mathrm{w})_{4}$ & Conf 1 & -2.8 \\
$(\mathrm{sa})_{2}(\mathrm{w})_{5}$ & Conf 6 & -2.2 \\
& & \\
$(\mathrm{sa})_{3}(\mathrm{w})_{1}$ & Conf 5 & -2.4 \\
$(\mathrm{sa})_{3}(\mathrm{w})_{2}$ & Conf 3 & -3.8 \\
$(\mathrm{sa})_{3}(\mathrm{w})_{3}$ & Conf 9 & -1.7 \\
$(\mathrm{sa})_{3}(\mathrm{w})_{4}$ & Conf 4 & -1.8 \\
$(\mathrm{sa})_{3}(\mathrm{w})_{5}$ & Conf 5 & -4.8 \\
& & \\
$(\mathrm{sa})_{4}(\mathrm{w})_{1}$ & Conf 2 & -0.9 \\
$(\mathrm{sa})_{4}(\mathrm{w})_{2}$ & Conf 4 & -6.9 \\
$(\mathrm{sa})_{4}(\mathrm{w})_{3}$ & Conf 4 & -3.8 \\
$(\mathrm{sa})_{4}(\mathrm{w})_{4}$ & Conf 1 & -9.1 \\
$(\mathrm{sa})_{4}(\mathrm{w})_{5}$ & Conf 9 & -7.1 \\
& &
\end{tabular}

Table 1 shows that the lowest free energy of the $n-1$ cluster only yields the lowest free energy 
$n$ cluster in the case of the $(\mathrm{sa})_{2}(\mathrm{w})_{4}$ and $(\mathrm{sa})_{4}(\mathrm{w})_{4}$ clusters. This shows that to locate the $n$ water cluster lowest in free energy additional local minima are required when adding another water molecule to the $n-1$ clusters. We have used a maximum of 10 conformers (with a cut-off in free energy at $3.0 \mathrm{kcal} / \mathrm{mol}$ ) and in the case of forming the $(\mathrm{sa})_{3}(\mathrm{w})_{3}$ and $(\mathrm{sa})_{4}(\mathrm{w})_{5}$ clusters conformation \#9 yields the lowest free energy cluster. This indicates that a larger pool than the 10 lowest structurally different conformations might be necessary in some cases. However, it is system specific at what point the number of initial conformers is sufficient with respect to obtaining the lowest possible free energy structure and including more initial conformers will at some point lead to sampling unimportant higher free energy minima on the free energy surface.

In all cases, we obtain a conformation that is lower in free energy than the one currently available in the cluster database. This is a clear illustration that the presented sampling methodology is reliably capable of locating low free energy cluster structures. However, we still can not guarantee that we have found the "true" global minima, but due to the exhaustive search algorithm presented here, we believe that we have found a minima close to it in free energy (although it might still be structurally different). Table 1 shows that we locate minima significantly lower in free energy than the clusters available in literature by up to $-9.1 \mathrm{kcal} / \mathrm{mol}$. This is an very significant difference and will certainly have an effect on the stability of the clusters. It should be noted that the structures in the database have been extracted from the work by Henschel et al. ${ }^{48}$ which have been sampled using chemical intuition and at a different level of theory (B3LYP/CBSB7). We only re-optimized the lowest free energy cluster found by Henschel et al. and hence, it is expected that the newly sampled structures are either identical or lower in free energy.

The newly sampled $(\mathrm{sa})_{2}(\mathrm{w})_{4-5}$ clusters are structurally slightly different from the clusters previously presented by Temelso et al. ${ }^{46}$ Re-optimizing the lowest free energy structures found by Temelso et al. at the DLPNO-CCSD $\left(\mathrm{T}_{0}\right) /$ aug-cc-pVTZ// $\mathrm{B} 97 \mathrm{X}-\mathrm{D} / 6-31++\mathrm{G}(\mathrm{d}, \mathrm{p})$ level of theory $(298.15 \mathrm{~K}$ and $1 \mathrm{~atm})$ confirms that the structures presented in Figure 2 
are slightly lower in free energy at this level, by $-0.3 \mathrm{kcal} / \mathrm{mol}$ and $-1.7 \mathrm{kcal} / \mathrm{mol}$ for the $(\mathrm{sa})_{2}(\mathrm{w})_{4}$ and $(\mathrm{sa})_{2}(\mathrm{w})_{5}$ clusters, respectively. As the free energy surface is very dependent on the applied level of theory, there could be numerous reasons to this slight discrepancy. Temelso et al. applied MP2/6-31+G(d) compared to $\omega$ B97X-D/6-31++G(d,p) used by us to optimize the cluster geometries. Furthermore, they applied scaling factors to the vibrational frequencies to account for anharmonic effects, while the corresponding scaling factor at the $\omega \mathrm{B} 97 \mathrm{X}-\mathrm{D} / 6-31++\mathrm{G}(\mathrm{d}, \mathrm{p})$ level of theory has been estimated to be close to unity. ${ }^{57}$ For the single point energies, Temelso et al. extrapolated the MP2/6-31+G(d) energies to the complete basis set limit using an 4-5 inverse polynomial extrapolation scheme. We apply DLPNO-CCSD $\left(\mathrm{T}_{0}\right)$ /aug-cc-pVTZ which might be more prone to basis set superposition errors, but has shown excellent performance compared to CCSD(T)/CBS estimates. ${ }^{63}$ The minor structural and free energy difference between Temelso et al. and the present study further illustrate how complex the potential free energy surface is, and how dependent it is on the applied methodology, even for these two component sulfuric acid - water clusters.

For the largest $(\mathrm{sa})_{2}(\mathrm{w})_{5},(\mathrm{sa})_{3}(\mathrm{w})_{5}$ and $(\mathrm{sa})_{4}(\mathrm{w})_{5}$ cluster hydrates we compared the applied sampling technique to directly sampling the hydrated clusters using ABCluster following the protocol from Kubečka et al. ${ }^{65}$ While being significantly more computationally demanding than direct sampling, the systematic sampling process presented here locates $(\mathrm{sa})_{2}(\mathrm{w})_{5},(\mathrm{sa})_{3}(\mathrm{w})_{5}$ and $(\mathrm{sa})_{4}(\mathrm{w})_{5}$ minimum cluster structures $-1.0,-2.4$, and $-1.1 \mathrm{kcal} / \mathrm{mol}$ lower in free energy, respectively, at the DLPNO-CCSD $\left(\mathrm{T}_{0}\right) /$ aug-cc-pVTZ// $\omega$ B97X-D/6$31++\mathrm{G}(\mathrm{d}, \mathrm{p})$ level of theory $(298.15 \mathrm{~K}$ and $1 \mathrm{~atm})$. The method presented here uses assumptions that make the addition of one water molecule computationally low but still reaching proper exploration of the potential free energy surface. The bottleneck becomes the sequential addition of more water molecules. Kubecka et al., on the other hand, show how to directly perform configurational sampling of clusters with arbitrary composition. To reach the same level of PES exploration as the method presented in this article, it would be orders of magnitude more computationally expensive to use the approach presented by Kubecka et 
$a l$.

\subsection{Thermochemistry}

Whether or not a given cluster hydrate is formed in the atmosphere depends on the stepwise reaction free energies for adding a water molecule to the cluster. The reaction free energy of the $n$ 'th hydrate is calculated as:

$$
\Delta G_{\text {water, add }}=\Delta G_{n}-\Delta G_{n-1}
$$

Here $\Delta G_{n}$ and $\Delta G_{n-1}$ are the binding free energies of the $n$ 'th and $n-1$ 'th hydrated clusters.

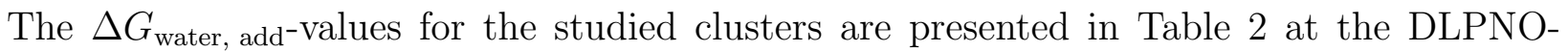
$\operatorname{CCSD}\left(\mathrm{T}_{0}\right) /$ aug-cc-pVTZ// $\omega$ B97X-D/6-31++G(d,p) level of theory, at 298.15 K and 1 atm. The Gibbs free energy data for the $(\mathrm{sa})_{1}(\mathrm{w})_{n}$ system is taken from Ref. 49.

Table 2: Stepwise reaction free energy $\left(\Delta G_{\text {water,add }}\right.$ in $\left.\mathrm{kcal} / \mathrm{mol}\right)$ for adding water molecules to the $(\mathrm{sa})_{2-4}$ clusters. Calculated at $298.15 \mathrm{~K}$ and $1 \mathrm{~atm}$. The Gibbs free energy values for the $(\mathrm{sa})_{1}(\mathrm{w})_{n}$ system is taken from reference 49 .

\begin{tabular}{ccccc}
\hline \hline$n$ & $(\mathrm{sa})_{1}(\mathrm{w})_{n}{ }^{49}$ & $(\mathrm{sa})_{2}(\mathrm{w})_{n}$ & $(\mathrm{sa})_{3}(\mathrm{w})_{n}$ & $(\mathrm{sa})_{4}(\mathrm{w})_{n}$ \\
\hline \hline 1 & -1.7 & -2.7 & -2.1 & -2.8 \\
2 & -1.0 & -2.5 & -2.4 & -5.2 \\
3 & -1.1 & -0.7 & -2.2 & -2.1 \\
4 & -1.1 & -0.9 & -2.4 & -2.4 \\
5 & 1.6 & -1.5 & -3.2 & -1.8
\end{tabular}

The clusters with several sulfuric acid molecules interact significantly stronger with water than a single sulfuric acid molecule. For the $(\mathrm{sa})_{2}(\mathrm{w})_{1}$ and $(\mathrm{sa})_{2}(\mathrm{w})_{2}$ clusters the $\Delta G_{\mathrm{water}}$ add is -2.7 and $-2.5 \mathrm{kcal} / \mathrm{mol}$, respectively, while it leads to a lower value in the range of 0.7 to $-1.5 \mathrm{kcal} / \mathrm{mol}$ the larger $(\mathrm{sa})_{2}(\mathrm{w})_{3-5}$ hydrate clusters. The $(\mathrm{sa})_{3}(\mathrm{w})_{1-5}$ clusters have water addition free energies ranging from $-2.1 \mathrm{kcal} / \mathrm{mol}$ to $-3.2 \mathrm{kcal} / \mathrm{mol}$. For the $(\mathrm{sa})_{4}(\mathrm{w})_{1-5}$ 
clusters the water addition free energy is also seen to be quite favourable, with a high peak value of $-5.2 \mathrm{kcal} / \mathrm{mol}$ for the $(\mathrm{sa})_{4}(\mathrm{w})_{2}$ cluster. Utilizing the calculated binding free energies, the cluster hydrate distributions can be calculated. The hydrate distribution $x_{n}$ of the $n$ 'th hydrate, is given by: 48

$$
x_{n}=\left(\frac{p\left(\mathrm{H}_{2} \mathrm{O}\right)}{p_{\text {ref }}}\right)^{n} x_{0} \exp \left(-\frac{\Delta G_{n}}{R T}\right)
$$

Here $\Delta G_{n}\left(\Delta G_{0}=0\right)$ is the binding free energy of the $n^{\prime}$ th hydrate cluster, $p_{\text {ref }}$ is the reference pressure for which the $\Delta G^{\prime}$ 's have been calculated (1 atm). The dry cluster $x_{0}$-value is set as a normalization constant so that the distributions sum up to one. The saturation vapour pressure (at $298.15 \mathrm{~K}$ ) of water is $p\left(\mathrm{H}_{2} \mathrm{O}\right)=0.0316$ atm. Figure 3 shows the calculated hydrate distributions for the $(\mathrm{sa})_{2}(\mathrm{w})_{1-5},(\mathrm{sa})_{3}(\mathrm{w})_{1-5}$ and $(\mathrm{sa})_{4}(\mathrm{w})_{1-5}$ clusters, at $50 \%, 75 \%$ and $100 \%$ relative humidity. 

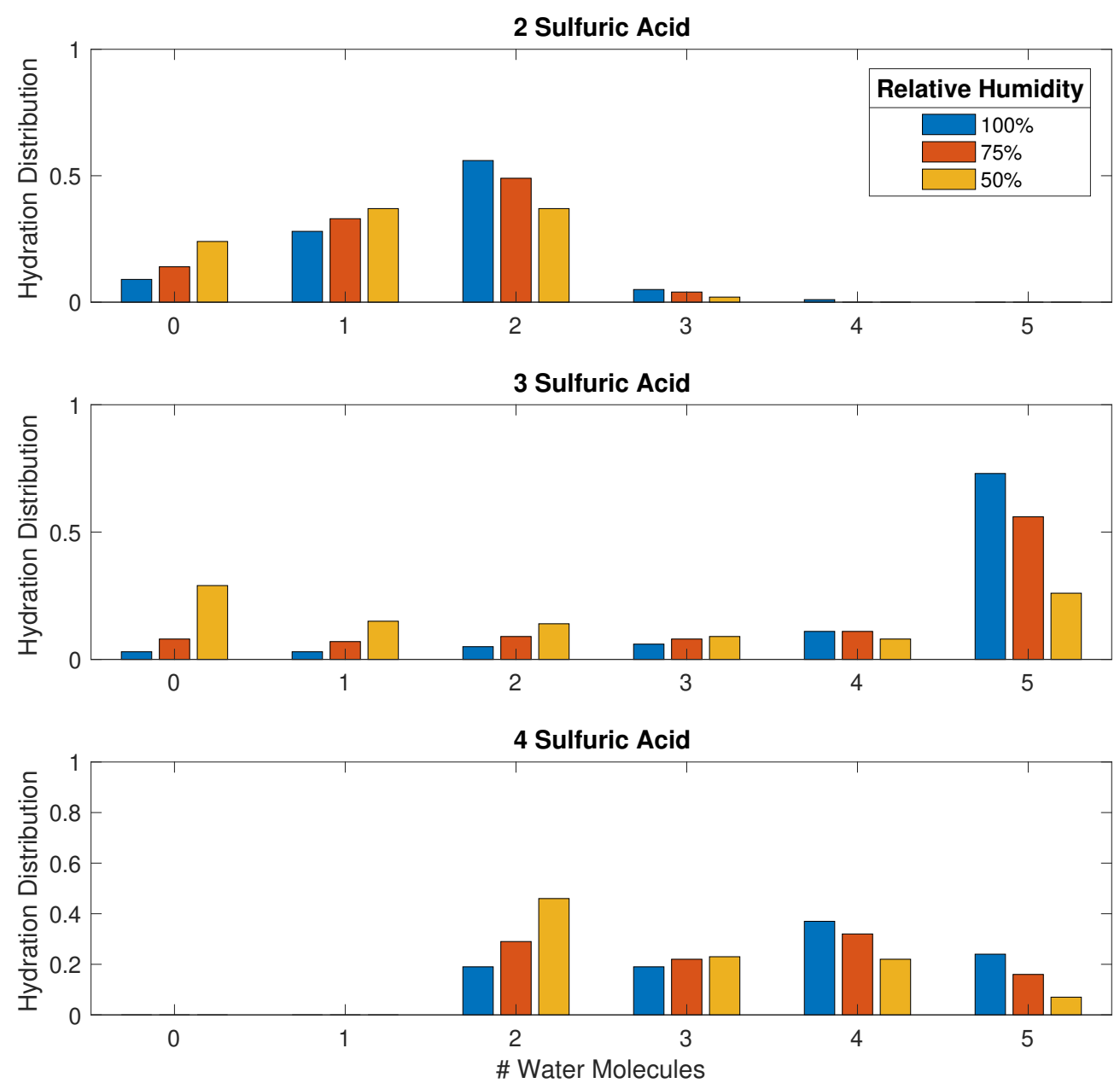

Figure 3: Hydrate distributions $\left(x_{n}\right)$ of the $(\mathrm{sa})_{2}(\mathrm{w})_{1-5},(\mathrm{sa})_{3}(\mathrm{w})_{1-5}$ and $(\mathrm{sa})_{4}(\mathrm{w})_{1-5}$ clusters. The distributions are calculated at 50\%, $75 \%$ and $100 \%$ relative humidity, at $298.15 \mathrm{~K}$.

For the $(\mathrm{sa})_{2}(\mathrm{w})_{0-5}$ system the most populated cluster types are the $(\mathrm{sa})_{2}(\mathrm{w})_{0-2}$, with only a minor contribution from the $(\mathrm{sa})_{2}(\mathrm{w})_{3-5}$ clusters. The $(\mathrm{sa})_{3}(\mathrm{w})_{5}$ cluster dominates the $(\mathrm{sa})_{3}(\mathrm{w})_{0-5}$ cluster distribution, with only a minor contribution from the other clusters. The $(\mathrm{sa})_{4}(\mathrm{w})_{0-5}$ clusters are also mainly hydrated with 2 to 5 water molecules. The fact that the hydrate distribution shifts from low hydration for the clusters with less sulfuric acid to higher level of hydration for the clusters with more sulfuric acid molecules indicates that it might be necessary to consider more than five water molecules for the clusters with many acid molecules. 


\subsection{Analysis of the Effect of Conformers on the Free Energies}

Conformers higher in free energy than the lowest free energy conformation contribute to the average free energy of the clusters. Since the sampling procedure generates a large pool of low free energy conformers we can include these into the calculations of the average binding free energies. As this involves considering the full set of 1145 isomers, this analysis has only been performed at the $\omega \mathrm{B} 97 \mathrm{X}-\mathrm{D} / 6-31++\mathrm{G}(\mathrm{d}, \mathrm{p})$ level of theory. The binding free energy considering multiple conformations ( $\left.\Delta G_{\text {multi-conf }}\right)$ can be calculated as: ${ }^{73}$

$$
\Delta G_{\text {multi-conf }}=-R T \ln \left[\sum_{n} \exp \left(\frac{-\Delta G_{n}}{R T}\right)\right]
$$

Considering more conformers in the calculation of the free energies will lead to a lowering of the free energy as more microstates becomes available. Figure 4 illustrates the effect of multiple conformers on the free energy of the clusters using the $(\mathrm{sa})_{2}(\mathrm{w})_{2}$ cluster as an example. The calculations are performed at $298.15 \mathrm{~K}$ and $1 \mathrm{~atm}$.

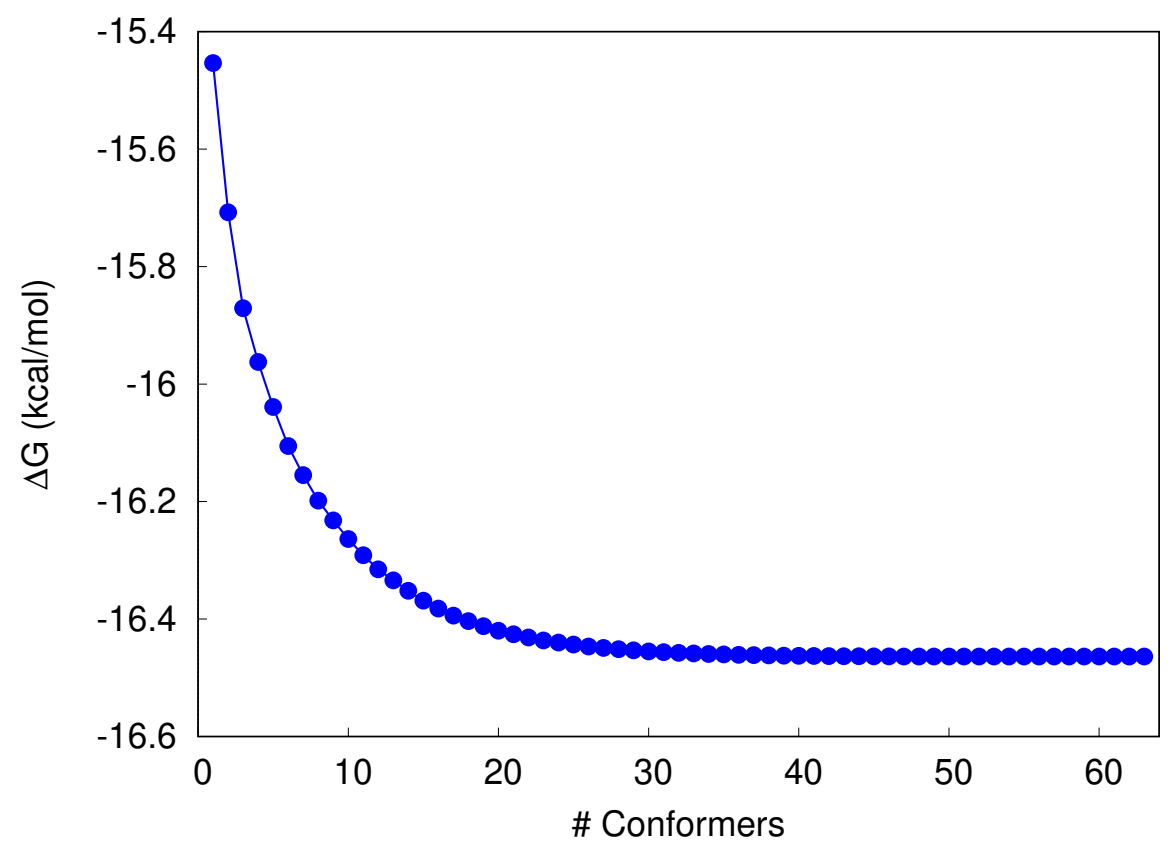

Figure 4: Example of the convergence of the binding free energy $\Delta G_{n}$ of the $(\mathrm{sa})_{2}(\mathrm{w})_{2}$ cluster as a function of the number of conformers included in the calculation. 
The binding free energy converges after including the $\sim 25$ lowest free energy conformers in the calculations. After this point the inclusion of higher free energy conformers contributes very little to the free energy (below $-0.01 \mathrm{kcal} / \mathrm{mol}$ ). The binding free energy contribution for including all the conformers $\left(\Delta \Delta G_{\text {multi-conf,corr }}\right)$ is calculated as:

$$
\Delta \Delta G_{\text {multi-conf,corr }}=\Delta G_{\text {multi-conf }}-\Delta G_{0},
$$

where $\Delta G_{0}$ is the binding free energy of the lowest free energy conformation. For instance, the difference between only including the lowest free energy conformer or including all $63(\mathrm{sa})_{2}(\mathrm{w})_{2}$ conformers as illustrated in Figure 4 leads to a $\Delta \Delta G_{\text {multi-conf,corr-value }}$ of $-1.0 \mathrm{kcal} / \mathrm{mol}$ difference in the binding free energy. Table 3 presents the calculated

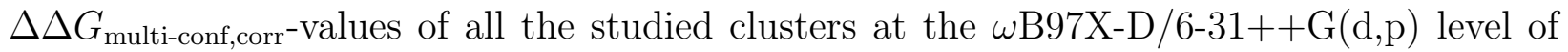
theory (298.15 K and $1 \mathrm{~atm})$.

Table 3: Binding free energy difference $\left(\Delta \Delta G_{\text {multi-conf,corr }}\right.$ in $\left.\mathrm{kcal} / \mathrm{mol}\right)$ between including only the lowest free energy conformation or all conformations. $n$ is the number of sulfuric acid molecules in the cluster. The number of identified conformers for each system is shown in the parenthesis.

\begin{tabular}{cccc}
\hline \hline Cluster & $n=2$ & $n=3$ & $n=4$ \\
\hline \hline$(\mathrm{sa})_{n}(\mathrm{w})_{1}$ & $-1.0(37)$ & $-0.9(65)$ & $-0.8(37)$ \\
$(\mathrm{sa})_{n}(\mathrm{w})_{2}$ & $-1.0(63)$ & $-0.4(104)$ & $-0.3(51)$ \\
$(\mathrm{sa})_{n}(\mathrm{w})_{3}$ & $-1.2(111)$ & $-0.5(123)$ & $-0.3(44)$ \\
$(\mathrm{sa})_{n}(\mathrm{w})_{4}$ & $-0.8(107)$ & $-0.6(114)$ & $-0.8(38)$ \\
$(\mathrm{sa})_{n}(\mathrm{w})_{5}$ & $-0.7(122)$ & $-0.5(77)$ & $-0.3(52)$
\end{tabular}

The effect of including all conformers is found to be $-1.2 \mathrm{kcal} / \mathrm{mol}$ or below. Within each cluster system the free energy of water addition deviates very little, on the order of -0.5 $\mathrm{kcal} / \mathrm{mol}$ or below. As this is similar in magnitude to the error expected from high level binding energies at the $\operatorname{CCSD}(\mathrm{T})$ level of theory, it is not worthwhile to exhaustively identify all low lying free energy minima as long as the lowest one can be identified. 


\section{Conclusions}

We present an efficient and systematic procedure for exploring the free energy surface of large hydrated atmospheric relevant clusters. The procedure combines the sampling of the dry clusters using the ABCluster program coupled with a systematic hydrate sampling technique. Using the dry $(\mathrm{sa})_{2-4}$ clusters as a test system we hydrate them with up to five water molecules leading to a large pool of 1145 unique $(\mathrm{sa})_{2-4}(\mathrm{w})_{1-5}$ clusters. We find that the presented sampling procedure locates conformers up to $-9.1 \mathrm{kcal} / \mathrm{mol}$ in free energy lower than the clusters currently available in the cluster database. This illustrates that the sampling procedure represents an efficient approach to study the complex free energy surface of large hydrated atmospheric clusters.

Using the calculated thermochemical data, the cluster hydrate distributions are presented. We find that the $(\mathrm{sa})_{2}(\mathrm{w})_{0-5}$ clusters are mainly hydrated by two or less water molecules. For the larger $(\mathrm{sa})_{3-4}(\mathrm{w})_{0-5}$ clusters the hydrate distribution is shifted towards the more hydrated clusters, which indicate that these clusters might not be completely saturated with the respect to the number of water molecules. This implies that more than five water molecules might be needed to take into consideration when studying large hydrated atmospheric molecular clusters. The presented methodology provides modellers means to take the effect of water genuinely into account in atmospheric particle formation models based on quantum chemical data. Furthermore, the methodology can efficiently be applied to clusters with other compositions and hydrated multicomponent clusters involving sulfuric acid, bases and water should be further investigated.

\section{Acknowledgement}

J.E. thanks the Independent Research Fund Denmark grant number 9064-00001B for financial support. J.K., V.B. and H.V. thank University of Helsinki, Faculty of Science, ATMATH project, and ERC grant no. 692891-DAMOCLES for funding. We thank the Danish 
e-Infrastructure Cooperation (DeiC) and Centre for Scientific Computing for computational resources.

\section{Supporting Information Available}

The following is available as supporting information:

xyz-files of all the studied molecular structures at the $\omega$ B97X-D/6-31++G(d,p) level of theory.

Gibbs free energies of all the identified cluster configurations at the $\omega$ B97X-D/6-31++G(d,p) level of theory.

\section{References}

(1) IPCC, 2013: Climate Change 2013: The Physical Science Basis. Contribution of Working Group I to the Fifth Assessment Report of the Intergovernmental Panel on Climate Change [Stocker, T.F., D. Qin, G.-K. Plattner, M. Tignor, S.K. Allen, J. Boschung, A. Nauels, Y. Xia, V. Bex and P.M. Midgley (eds.)]. Cambridge University Press, Cambridge, United Kingdom and New York, NY, USA, 1535 pp.

(2) Merikanto, J.; Spracklen, D. V.; Mann, G. W.; Pickering, S. J.; Carslaw, K. S. Impact of nucleation on global CCN. Atmos. Chem. Phys. 2009, 9, 8601-8616.

(3) Kulmala, M.; Kontkanen, J.; Junninen, H.; Lehtipalo, K.; Manninen, H. E.; Nieminen, T.; Petäjä, T.; Sipilä, M.; Schobesberger, S.; Rantala, P. et al. Direct Observations of Atmospheric Aerosol Nucleation. Science 2013, 339, 943-946.

(4) Sipilä, M.; Berndt, T.; Petäjä, T.; Brus, D.; Vanhanen, J.; Stratmann, F.; Patokoski, J.; Mauldin, R. L.; Hyvärinen, A.-P.; Lihavainen, H. et al. The Role of Sulfuric Acid in Atmospheric Nucleation. Science 2010, 327, 1243-1246. 
(5) Arnold, F.; Fabian, R. First Measurements of Gas Phase Sulphuric Acid in the Stratosphere. Nature 1980, 283, 55-57.

(6) Weber, R. J.; Marti, J. J.; McMurry, P. H.; Eisele, F. L.; Tanner, D. J.; Jefferson, A. Measured Atmospheric New Particle Formation Rates: Implications for Nucleation Mechanisms. Chem. Eng. Comm. 1996, 151, 53-64.

(7) Marti, J. J.; Weber, R. J.; McMurry, P. H.; Eisele, F.; Tanner, D.; Jefferson, A. New Particle Formation at a Remote Continental Site: Assessing the Contributions of $\mathrm{SO}_{2}$ and Organic Precursors. J. Geophys. Res. 1997, 102, 6331-6339.

(8) Kurtén, T.; Loukonen, V.; Vehkamäki, H.; Kulmala, M. Amines are Likely to Enhance Neutral and Ion-induced Sulfuric Acid-water Nucleation in the Atmosphere More Effectively than Ammonia. Atmos. Chem. Phys. 2008, 8, 4095-4103.

(9) Nadykto, A. B.; Yu, F.; Jakovleva, M. V.; Herb, J.; Xu, Y. Amines in the Earth's Atmosphere: A Density Functional Theory Study of the Thermochemistry of PreNucleation Clusters. Entropy 2011, 13, 554-569.

(10) Almeida, J.; Schobesberger, S.; Kürten, A.; Ortega, I. K.; Kupiainen-Määttä, O.; Praplan, A. P.; Adamov, A.; Amorim, A.; Bianchi, F.; Breitenlechner, M. et al. Molecular Understanding of Sulphuric Acid-Amine Particle Nucleation in the Atmosphere. Nature 2013, 502, 359-363.

(11) Jen, C. N.; McMurry, P. H.; Hanson, D. R. Stabilization of Sulfuric acid Dimers by Ammonia, Methylamine, Dimethylamine, and Trimethylamine. J Geophys. Res. Atmos. $\mathbf{2 0 1 4}, 119,7502-7514$.

(12) Nadykto, A. B.; Herb, J.; Yu, F.; Xu, Y. Enhancement in the Production of Nucleating Clusters due to Dimethylamine and Large Uncertainties in the Thermochemistry of Amine-Enhanced Nucleation. Chem. Phys. Lett. 2014, 609, 42-49. 
(13) Glasoe, W. A.; Volz, K.; Panta, B.; Freshour, N.; Bachman, R.; Hanson, D. R.; McMurry, P. H.; Jen, C. Sulfuric Acid Nucleation: An Experimental Study of the Effect of Seven Bases. J. Geophys. Res. Atmos. 2015, 120, 1933-1950.

(14) Nadykto, A. B.; Herb, J.; Yu, F.; Xu, Y.; Nazarenko, E. S. Estimating the Lower Limit of the Impact of Amines on Nucleation in the Earth's Atmosphere. Entropy 2015, 17, $2764-2780$.

(15) Jen, C. N.; Bachman, R.; Zhao, J.; McMurry, P. H.; Hanson, D. R. Diamine-Sulfuric Acid Reactions are a Potent Source of New Particle Formation. Geophys. Res. Lett. 2016, 43, 867-873.

(16) Elm, J.; Jen, C. N.; Kurtén, T.; Vehkamäki, H. Strong Hydrogen Bonded Molecular Interactions between Atmospheric Diamines and Sulfuric Acid. J. Phys. Chem. A 2016, 120, 3693-3700.

(17) Elm, J.; Passananti, M.; Kurtén, T.; Vehkamäki, H. Diamines Can Initiate New Particle Formation in the Atmosphere. J. Phys. Chem. A 2017, 121, 6155-6164.

(18) Myllys, N.; Chee, S.; Olenius, T.; Lawler, M.; Smith, J. Molecular-Level Understanding of Synergistic Effects in Sulfuric Acid-Amine-Ammonia Mixed Clusters. J. Phys. Chem. A 2019, 123, 2420-2425.

(19) Myllys, N.; Kubečka, J.; Besel, V.; Alfaouri, D.; Olenius, T.; Smith, J. N.; Passananti, M. Role of Base Strength, Cluster Structure and Charge in SulfuricAcid-Driven Particle Formation. Atmos. Chem. Phys. 2019, 19, 9753-9768.

(20) Hemmilä, M.; Makkonen, U.; Virkkula, A.; Panagiotopoulou, G.; Aalto, J.; Kulmala, M.; Petäjä, T.; Hakola, H.; Hellén, H. Amine and guanidine emissions from a boreal forest floor. Atmos. Chem. Phys. Discuss. 2020, https://doi.org/10.5194/acp2019-1157. 
(21) Yang, Y.; Waller, S. E.; Kreinbihl, J. J.; Johnson, C. J. Direct Link between Structure and Hydration in Ammonium and Aminium Bisulfate Clusters Implicated in Atmospheric New Particle Formation. J. Phys. Chem. Lett. 2018, 9, 5647-5652.

(22) Waller, S. E.; Yang, Y.; Castracane, E.; Racow, E. E.; Kreinbihl, J. J.; Nickson, K. A.; Johnson, C. J. The Interplay Between Hydrogen Bonding and Coulombic Forces in Determining the Structure of Sulfuric Acid-Amine Clusters. J. Phys. Chem. Lett. 2018, 9, 1216-1222.

(23) Jokinen, T.; Sipilä, M.; Junninen, H.; Ehn, M.; Lönn, G.; Hakala, J.; Petäjä, T.; Mauldin III, R. L.; Kulmala, M.; Worsnop, D. R. Atmospheric Sulphuric Acid and Neutral Cluster Measurements Using CI-APi-TOF. Atmos. Chem. Phys. 2012, 12, $4117-4125$.

(24) Zapadinsky, E.; Passananti, M.; Myllys, N.; Kurtén, T.; Vehkamäki, H. Modeling on Fragmentation of Clusters inside a Mass Spectrometer. J. Phys. Chem. A 2019, 123, $611-624$.

(25) Passananti, M.; Zapadinsky, E.; Zanca, T.; Kangasluoma, J.; Myllys, N.; Rissanen, M. P.; Kurtén, T.; Ehn, M.; Attouid, M.; Vehkamäki, H. How Well Can We Predict Cluster Fragmentation Inside a Mass Spectrometer? Chem.Commun. 2019, $55,5946-5949$.

(26) Ehn, M.; Junninen, H.; Petäjä, T.; Kurtén, T.; Kerminen, V.-M.; Schobesberger, S.; Manninen, H. E.; Ortega, I. K.; Vehkamäki, H.; Kulmala, M. et al. Composition and Temporal Behavior of Ambient Ions in the Boreal Forest. Atmos. Chem. Phys. 2010, $10,8513-8530$.

(27) Schobesberger, S.; Junninen, H.; Bianchi, F.; Lönn, G.; Ehn, M.; Lehtipalo, K.; Dommen, J.; Ehrhart, S.; Ortega, I. K.; Franchin, A. et al. Molecular Understanding 
of Atmospheric Particle Formation from Sulfuric Acid and Large Oxidized Organic Molecules. Proc. Natl. Acad. Sci. U.S.A. 2013, 110, 17223-17228.

(28) Xantheas, S. S.; Dunning, T. H. Ab Initio Studies of Cyclic Water Clusters $\left(\mathrm{H}_{2} \mathrm{O}\right) n$, $n=1$-6. I. Optimal Structures and Vibrational Spectra. J. Chem. Phys. 1993, 99, $8774-8792$.

(29) Xantheas, S. S. Ab Initio Studies of Cyclic Water Clusters $\left(\mathrm{H}_{2} \mathrm{O}\right) n, n=1-6$. II. Analysis of Many-body Interactions. J. Chem. Phys. 1994, 100, 7523-7534.

(30) Xantheas, S. S. Ab Initio Studies of Cyclic Water Clusters $\left(\mathrm{H}_{2} \mathrm{O}\right) n, n=1-6$. III. Comparison of Density Functional with MP2 Results. J. Chem. Phys. 1995, 102, 45054517.

(31) S.Yoo,; Aprá, E.; Zeng, X. C.; ; Xantheas, S. S. High-Level Ab Initio Electronic Structure Calculations of Water Clusters $\left(\mathrm{H}_{2} \mathrm{O}\right)_{16}$ and $\left(\mathrm{H}_{2} \mathrm{O}\right)_{17}$ : A New Global Minimum for $\left(\mathrm{H}_{2} \mathrm{O}\right)_{16}$. J. Phys. Chem. Lett. 2010, 1, 3122-3127.

(32) Shields, R. M.; Temelso, B.; Archer, K. A.; Morrell, T. E.; Shields, G. C. Accurate Predictions of Water Cluster Formation, $\left(\mathrm{H}_{2} \mathrm{O}\right)_{n=2-10}$. J. Phys. Chem. A 2010, 114, $11725-11737$.

(33) Pérez, C.; Muckle, M. T.; Zaleski, D. P.; Seifert, N. A.; Temelso, B.; Shields, G. C.; Kisiel, Z.; Pate, B. H. Structures of Cage, Prism, and Book Isomers of Water Hexamer from Broadband Rotational Spectroscopy. Science 2012, 336, 897-901.

(34) Manna, D.; Kesharwani, M. K.; Sylvetsky, N.; Martin, J. M. L. Conventional and Explicitly Correlated ab Initio Benchmark Study on Water Clusters: Revision of the BEGDB and WATER27 Data Sets. J. Chem. Theory Comput. 2017, 13, 3136-3152.

(35) Temelso, B.; Klein, K. L.; Mabey, J. W.; Pérez, C.; Pate, B. H.; Kisiel, Z.; Shields, G. C. 
Exploring the Rich Potential Energy Surface of $\left(\mathrm{H}_{2} \mathrm{O}\right)_{11}$ and Its Physical Implications. J. Chem. Theory Comput. 2018, 14, 1141-1153.

(36) Malloum, A.; Fifen, J. J.; Dhaouadi, Z.; Engo, S. G. N.; Conradie, J. Structures, Relative Stability and Binding Energies of Neutral Water Clusters, (H2O)2-30. New J. Chem. 2019, 43, 13020-13037.

(37) Kurdi, L.; Kochanski, E. Theoretical Studies of Sulfuric Acid Monohydrate: Neutral or Ionic Complex? Chem. Phys. Lett. 1989, 158, 111-115.

(38) Arstila, H.; Laasonen, K.; Laaksonen, A. Ab Initio Study of Gas-Phase Sulphuric Acid Hydrates Containing 1 to 3 Water Molecules. J. Chem. Phys. 1998, 108, 1031-1039.

(39) Bandy, A. R.; Ianni, J. C. Study of the Hydrates of $\mathrm{H}_{2} \mathrm{SO}_{4}$ using Density Functional Theory. J. Phys. Chem. A 1998, 102, 6533-6539.

(40) Re, S.; Osamurał, Y.; Morokuma, K. Coexistence of Neutral and Ion-Pair Clusters of Hydrated Sulfuric Acid $\mathrm{H}_{2} \mathrm{SO}_{4}\left(\mathrm{H}_{2} \mathrm{O}\right)_{n}(n=1-5)$ - A Molecular Orbital Study. J. Phys. Chem. A 1999, 103, 3535-3547.

(41) Ding, G.; Laasonen, K. Partially and Fully Deprotonated Sulfuric Acid in $\mathrm{H}_{2} \mathrm{SO}_{4}\left(\mathrm{H}_{2} \mathrm{O}\right)_{n}$ $(n=6-8)$ Clusters. Chem. Phys. Lett. 2004, 390, 307-313.

(42) Kurtén, T.; Noppel, M.; Vehkamäki, H.; Salonen, M.; Kulmala, M. Quantum Chemical Studies of Hydrate Formation of $\mathrm{H}_{2} \mathrm{SO}_{4}$ and $\mathrm{HSO}_{4}^{-}$. Boreal Environ. Res. 2007, 12, $431-453$.

(43) Temelso, B.; Morrell, T. E.; Shields, R. M.; Allodi, M. A.; Wood, E. K.; Kirschner, K. N.; Castonguay, T. C.; Archer, K. A.; Shields, G. C. Quantum Mechanical Study of Sulfuric Acid Hydration: Atmospheric Implications. J. Phys. Chem. A. 2012, 116, 2209-2224. 
(44) Ianni, J. C.; Bandy, A. R. A Theoretical Study of the Hydrates of $\left(\mathrm{H}_{2} \mathrm{SO}_{4}\right)_{2}$ and its Implications for the Formation of New Atmospheric Particles. J. Mol. Struc-THEOCHEM 2000, 497, 19-37.

(45) Ding, G.; Laasonen, K.; Laaksonen, A. Two Sulfuric Acids in Small Water Clusters. J. Phys. Chem. A 2003, 107, 8648-8658.

(46) Temelso, B.; Phan, T. N.; Shields, G. C. Computational Study of the Hydration of Sulfuric Acid Dimers: Implications for Acid Dissociation and Aerosol Formation. J. Phys. Chem. A. 2012, 116, 9745-9758.

(47) Loukonen, V.; Kurtén, T.; Ortega, I. K.; Vehkamäki, H.; Pádua, A. A. H.; Sellegri, K.; Kulmala, M. Enhancing Effect of Dimethylamine in Sulfuric Acid Nucleation in the Presence of Water - A Computational Study. Atmos. Chem. Phys. 2010, 10, 49614974 .

(48) Henschel, H.; Navarro, J. C. A.; Yli-Juuti, T.; Kupiainen-Määttä, O.; Olenius, T.; Ortega, I. K.; Clegg, S. L.; Kurtén, T.; Riipinen, I.; Vehkamäki, H. Hydration of Atmospherically Relevant Molecular Clusters: Computational Chemistry and Classical Thermodynamics. J. Phys. Chem. A. 2014, 118, 2599-2611.

(49) Kildgaard, J. V.; Mikkelsen, K. V.; Bilde, M.; Elm, J. Hydration of Atmospheric Molecular Clusters: A New Method for Systematic Configurational Sampling. J. Phys. Chem. A 2018, 122, 5026-5036.

(50) Kildgaard, J. V.; Mikkelsen, K. V.; Bilde, M.; Elm, J. Hydration of Atmospheric Molecular Clusters II: Organic Acid-Water Clusters. J. Phys. Chem. A 2018, 122, 8549-8556.

(51) Zhang, J.; Dolg, M. ABCluster: The Artificial Bee Colony Algorithm for Cluster Global Optimization. Phys. Chem. Chem. Phys. 2015, 17, 24173-24181. 
(52) Zhang, J.; Dolg, M. Global Optimization of Clusters of Rigid Molecules Using the Artificial Bee Colony Algorithm. Phys. Chem. Chem. Phys. 2016, 18, 3003-3010.

(53) Gaussian 16, Revision A.03, M. J. Frisch, G. W. Trucks, H. B. Schlegel, G. E. Scuseria, M. A. Robb, J. R. Cheeseman, G. Scalmani, V. Barone, G. A. Petersson, H. Nakatsuji, et al., Gaussian, Inc., Wallingford CT, 2016.

(54) Gaussian 09, Revision B.01, M. J. Frisch, G. W. Trucks, H. B. Schlegel, G. E. Scuseria, M. A. Robb, J. R. Cheeseman, G. Scalmani, V. Barone, B. Mennucci, G. A. Petersson, et al., Gaussian, Inc., Wallingford CT, 2010.

(55) Elm, J.; Bilde, M.; Mikkelsen, K. V. Assessment of Binding Energies of Atmopsheric Clusters. Phys. Chem. Chem. Phys 2013, 15, 16442-16445.

(56) Elm, J.; Kristensen, K. Basis Set Convergence of the Binding Energies of Strongly Hydrogen-Bonded Atmospheric Clusters. Phys. Chem. Chem. Phys 2017, 19, 11221133.

(57) Myllys, N.; Elm, J.; Kurtén, T. Density Functional Theory Basis Set Convergence of Sulfuric Acid-Containing Molecular Clusters. Comp. Theor. Chem. 2016, 1098, 1-12.

(58) Elm, J.; Mikkelsen, K. V. Computational Approaches for Efficiently Modelling of Small Atmospheric Clusters. Chem. Phys. Lett. 2014, 615, 26-29.

(59) Riplinger, C.; Neese, F. An Efficient and Near Linear Scaling Pair Natural Orbital Based Local Coupled Cluster Method. J. Chem. Phys. 2013, 138, 034106.

(60) Riplinger, C.; Sandhoefer, B.; Hansen, A.; Neese, F. Natural Triple Excitations in Local Coupled Cluster Calculations with Pair Natural Orbitals. J. Chem. Phys. 2013, 139, 134101.

(61) Guo, D. G. L. Y.; Neese, F. Comprehensive Benchmark Results for the Domain Based 
Local Pair Natural Orbital Coupled Cluster Method (DLPNO-CCSD(T)) for Closedand Open-Shell Systems. J. Phys. Chem. A 2020, 124, 90-100.

(62) Liakos, D. G.; Sparta, M.; Kesharwani, M. K.; Martin, J. M. L.; Neese, F. Exploring the Accuracy Limits of Local Pair Natural Orbital Coupled-Cluster Theory. J. Chem. Theory. Comput. 2015, 11, 1525-1539.

(63) Schmitz, G.; Elm, J. Assessment of the DLPNO Binding Energies of Strongly NonCovalent Bonded Atmospheric Molecular Clusters. ACS Omega 2020, 5, 7601-7612.

(64) Guo, Y.; Riplinger, C.; Becker, U.; Liakos, D. G.; Minenkov, Y.; Cavallo, L.; Neese, F. Communication: An Improved Linear Scaling Perturbative Triples Correction for the Domain Based Local Pair-natural Orbital Based Singles and Doubles Coupled Cluster Method [DLPNO-CCSD(T)]. J. Chem. Phys. 2018, 148, 011101.

(65) Kubečka, J.; Besel, V.; Kurtén, T.; Myllys, N.; Vehkamäki, H. Configurational Sampling of Noncovalent (Atmospheric) Molecular Clusters: Sulfuric Acid and Guanidine. J. Phys. Chem. A 2019, 123, 6022-6033.

(66) Grimme, S.; Bannwarth, C.; Shushkov, P. A Robust and Accurate Tight-Binding Quantum Chemical Method for Structures, Vibrational Frequencies, and Noncovalent Interactions of Large Molecular Systems Parametrized for All spd-Block Elements ( $\mathrm{Z}=$ 1-86). J. Chem. Theory Comput. 2017, 13, 1989-2009.

(67) Stewart, J. J. P. Optimization of Parameters for Semiempirical Methods VI: More Modifications to the NDDO Approximations and Re-optimization of Parameters. $J$. Mol. Model. 2013, 19, 1-32.

(68) Temelso, B.; Morrison, E. F.; Speer, D. L.; Cao, B. C.; Appiah-Padi, N.; Kim, G.; Shields, G. C. Effect of Mixing Ammonia and Alkylamines on Sulfate Aerosol Formation. J. Phys. Chem. A 2018, 122, 1612-1622. 
(69) Myllys, N.; Elm, J.; Halonen, R.; Kurtén, T.; Vehkamäki, H. Coupled Cluster Evaluation of the Stability of Atmospheric Acid-Base Clusters with up to 10 Molecules. J. Phys. Chem. A 2016, 120, 621-630.

(70) Elm, J. An Atmospheric Cluster Database Consisting of Sulfuric Acid, Bases, Organics, and Water. ACS Omega 2019, 4, 10965-10974.

(71) Yacovitch, T. I.; Heine, N.; Brieger, C.; Wende, T.; Hock, C.; Neumark, D. M.; Asmis, K. R. Vibrational Spectroscopy of Bisulfate/Sulfuric Acid/Water Clusters: Structure, Stability, and Infrared Multiple-Photon Dissociation Intensities. J.Phys.Chem.A 2013, 117, 7081-7090.

(72) Yang, Y.; Johnson, C. J. Hydration Motifs of Ammonium Bisulfate Clusters of Relevance to Atmospheric New Particle Formation. Faraday Discuss. 2019, 217, 47-66.

(73) Partanen, L.; Vehkamäki, H.; K. Hansen, H. H., J. Elm; Kurtén, T.; Halonen, R.; Zapadinsky, E. Effect of Conformers on Free Energies of Atmospheric Complexes. J. Phys. Chem. A 2016, 120, 8613-8624. 


\section{Graphical TOC Entry}

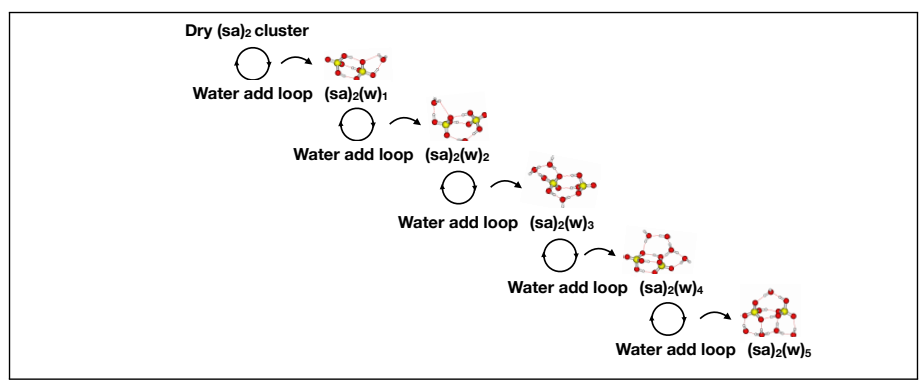

